\title{
In vitro Evaluation of Cytotoxic and Thrombolytic Activities of Oroxylum indicum (Linn.)
}

\author{
Md. Rabiul Islam ${ }^{1}$, A.S.M. Ali Reza ${ }^{1}$, Md. Sajjad Hossain ${ }^{1}$ and Mst. Kaniz Farhana ${ }^{2}$ \\ ${ }^{1}$ Department of Pharmacy, International Islamic University Chiitagong, Chittagong, Bangladesh \\ ${ }^{2}$ Department of Chemistry, University of Rajshahi, Rajshahi-6205, Bangladesh
}

\begin{abstract}
Oroxylum indicum is a species of flowering plant belonging to the family Bignoniaceae and have many medicinal properties which prompted us to evaluate its possible thrombolytic and cytotoxic activities. A quick and rapid methodology was applied to find out the thrombolytic effect of the methanol extract of leaves of $O$. indicum. Streptokinase and water were employed as a positive and negative control, respectively. Thrombolytic effect was expressed as percentage of clot lysis. $O$. indicum, streptokinase and water demonstrated $23.69 \pm 6.97 \%, 78.41 \pm 0.366 \%$ and $5.19 \pm 0.241 \%$ clot lysis, respectively. Cytotoxic property was evaluated by the brine shrimp lethality bioassay and the result was expressed as $\mathrm{LC}_{50}$. In this study, DMSO was used as solvent and vincristine sulphate as positive control. The extract showed cytotoxicity against brine shrimp nauplii and the calculated $\mathrm{LC}_{50}$ of $O$. indicum and vincristine sulphate were $251.2 \mu \mathrm{g} / \mathrm{ml}$ and $5.2 \mu \mathrm{g} / \mathrm{ml}$, respectively. Due to the cytotoxic and thrombolytic activities, $O$. indicum may be regarded as a promising candidate for natural anticancer agent and should be subjected to purification processes for useful therapeutic drugs.
\end{abstract}

Key words: Oroxylum indicum, Cytotoxicity, Thrombolytic, Cancer, $\mathrm{LC}_{50}$, Clot lysis.

\section{Introduction}

Cardiovascular diseases are one of the major health problems throughout the world. It is emerging as a serious health problem in Bangladesh and other developing countries. Amongst the heart diseases hypertension, ischemic heart diseases and congenital heart diseases are common. Latest survey on cardiovascular diseases carried out in Bangladesh showed prevalence of hypertension in about 20-25\% of adult population, Ischemic Heart Disease in about $10 \%$ of adult population. Venous thromboembolism (VTE) is a major public health problem worldwide, contributing to an estimated $>500,000$ deaths in Europe and up to 300,000 deaths in the United States each year (Heit et al., 2005). VTE creates a major burden on healthcare systems (Guanella et al., 2011). One of the major causes of blood circulation problem is the formation of blood clots. Thrombi or emboli can lodge in a blood vessel and block the flow of blood in that location depriving tissues of normal blood flow and oxygen. This can result in damage, destruction (infarction), or even death of the tissues (necrosis) in that area. A blood clot (thrombus) is formed from fibrinogen by thrombin and is lysed by plasmin, which is activated from plasminogen by tissue plasminogenactivator (tPA). Fribrinolytic drugs has been used to dissolve thrombi in acutely occluded coronary arteries there by to restore blood supply to ischemic myocardium, to limit necrosis and to improve prognosis (Laurence, 1992). Thrombolysis, also known as thrombolytic therapy, is a treatment to dissolve dangerous clots in blood vessels, improve blood flow and often used as an emergency treatment to dissolve blood clots in arteries feeding the heart and brain. Association between activation of blood coagulation and progression of cancer is supported by epidemiologic, laboratory, pathologic and clinical evidence. The increased risk for venous thromboembolism (VTE) in cancer has been considered an epiphenomenon (Rickles, 2006) and cancer is the sixth leading cause of death in Bangladesh. As a member of LDC, most of the people of Bangladesh are unable to bear the high cost of cardiovascular diseases as well as cancer treatment but this country is very rich in traditional medicines and has more than one thousand medicinal plants

Correspondence to: Md. Rabiul Islam, Cell: +8801911018901, E-mail: rabi6686@gmail.com 
(Mukul and Uddin, 2007) and a large majority (75$80 \%$ ) of the population of this country still prefer traditional medicine in the treatment of most of their diseases (Ghani, 1992).

$O$. indicum is a species of flowering plant belonging to the family Bignoniaceae (Jacaranda family) and it has lot of medicinal properties like antioxidant, anti-inflammatory, anti-diabetic and anti hyperlipidemic activities and most of the research have been performed with the stem bark or root bark extracts (Ahad et al., 2012). The plant also has traditional use as potent anticancer drug. Those medicinal properties of $O$. indicum inspired us to study the thrombolytic and cytotoxic activities of leaf extract.

\section{Materials and Methods}

Collection and identification: The leaves of the plant were collected from Chittagong hill tracts near Kumira, Sitakund. Herberium sheet was prepared and sample was identified by Dr. Shaikh Bokhtear Uddin, Department of Botany, Chittagong University, Bangladesh. These were sun dried and finally dried in an oven. The leaves were ground to a coarse powder and stored in an air tight container for further use.

Preparation of plant extract: $250 \mathrm{gm}$ powder of plant material was taken and soaked in $750 \mathrm{ml}$ of methanol for 4 days. It was shaken periodically and filtered by cotton followed by filter paper. The filtrate was concentrated to small volume removing entire methanol by using rotary evaporator. Then the thick, gummy extract was stored in a refrigerator for future studies.

Brine shrimp lethality assay: Brine shrimp eggs, Artemia salina were hatched in artificial sea water prepared by dissolving $38 \mathrm{~g}$ of sea salt in $1 \mathrm{~L}$ of distilled water. After 36 hours incubation at room temperature $\left(25^{\circ} \mathrm{C}-29^{\circ} \mathrm{C}\right)$ the larvae were attracted to one side of the vessel with a light source and collected with pipette. Larvae were separated from eggs by aliquoting them three times in small beakers containing seawater.

Cytotoxic activity of the plant extract was evaluated according to the procedure described by Meyer et al. (1982). The test samples (extract) were prepared by dissolving them in DMSO (not more than $50 \mu \mathrm{l}$ in $5 \mathrm{ml}$ solution) plus sea water $(3.8 \% \mathrm{NaCl}$ in water) to attain concentrations 1000-,
800-, 600-, 400-, 200-, 100-, 50- and 25- $\mu \mathrm{g} / \mathrm{ml}$. A vial containing $50 \mu \mathrm{l}$ DMSO diluted to $5 \mathrm{ml}$ was used as negative control and vincristine sulphate was used as negative control (Apu et al., 2010) was used as positive control. Then 10 brine shrimps were applied to each of all experimental and control vial. After 24 hrs, the vials were inspected by using a magnifying glass and the number of survived naupili in each vial was counted. The mortality end point of this bioassay was defined as the absence of control forward motion during 30s observation. From this data the percent of lethality of the brine shrimp naupili for each concentration and control was calculated. Statistical method of probit analysis (Finney, 1952) was used to calculate $\mathrm{LC}_{50}$. Criterion of toxicity for fractions was established according to (Déciga-campos et al., 2006): $\mathrm{LC}_{50}$ values $>1000 \mu \mathrm{g} / \mathrm{ml}$ (non-toxic), $\geq 500 \leq$ $1000 \mu \mathrm{g} / \mathrm{ml}$ (weak toxicity) and $<500 \mu \mathrm{g} / \mathrm{ml}$ (toxic).

Thrombolytic activity: This test was performed according to the method described by Prasad et al. (2006). With all aseptic condition whole blood was drawn from healthy human volunteers $(n=10)$ without a history of oral contraceptive or anticoagulant therapy and $1.0 \mathrm{ml}$ of blood was transferred to the previously weighed microcentrifuge tubes and was allowed to clot and incubated at $37^{\circ} \mathrm{C}$ for 45 minutes. After clot formation, the serum was completely removed without disturbing the clot. Now the microcentrifuge tubes were weighted again to get the weight of clot. The extract $(100 \mathrm{mg})$ from each plant was suspended in $10 \mathrm{ml}$ of distilled water and it was kept overnight and the soluble supernatant was decanted and filtered. Then each Eppendorf tube containing pre weighed clot, $100 \mu$ aqueous extract of $O$. indicum was added separately. As a negative control $100 \mu \mathrm{l}$ of distilled water was added to the control tubes. To lyophilized streptokinase vial (1500000 IU) $5 \mathrm{ml}$ sterile distilled water was added and mixed properly and from this solution $100 \mu$ l was added to the control tubes and used as positive control. All the tubes were then incubated at 37 for 90 minutes and observed for clot lysis. After incubation, supernatant fluid released was removed and tubes were again weighted to observe the difference in weight after clot disruption. Difference obtained in weight taken before and after clot lysis was expressed as percentage of clot lysis as shown below:

$\%$ Clot lysis $=($ wt of released clot $/$ clot $w t) \times 100$ 
Statistical analysis: All the results obtained by in vitro experiment were expressed as mean \pm STD of three measurements followed by Dunnet's test where $\mathrm{P}<0.01$ was considered as statistically significant

\section{Results}

Brine shrimps lethality test: The brine shrimps lethality test showed that $\%$ mortality increased gradually with the increase in concentration of the test samples (Table 1). Analyzing log concentration versus probit value (Figure 1) $\mathrm{LC}_{50}$ of the plant extract was $251.2 \mu \mathrm{g} / \mathrm{ml}$, where $\mathrm{LC}_{50}$ of standard vincristine sulphate was $5.20 \mu \mathrm{g} / \mathrm{ml}$ (Figure 2).

Thrombolytic activity: Thrombolytic activity of the plant extract varied with the individual volunteer from a maximum value of 34.12 to a minimum value of 12.46 percentage (Table 2). The average percentage of clot lysis was 23.697 with standard deviation 6.97, where percentage of cloy lysis by streptokinase and distilled water were $78.41 \pm 0.366$ and $5.19 \pm 0.241$, respectivly (Figure 3 ).
Table 1. Effect of methanol extract $O$. indicum on brine shrimp nauplii.

\begin{tabular}{ccccc}
\hline $\begin{array}{c}\text { Concentration } \\
\mu \mathrm{g} / \mathrm{ml}\end{array}$ & $\log \mathrm{C}$ & $\begin{array}{c}\text { \% of } \\
\text { mortality }\end{array}$ & $\begin{array}{c}\text { Probit } \\
\text { value }\end{array}$ & $\begin{array}{c}\mathrm{LC}_{50} \\
\mu \mathrm{g} / \mathrm{ml}\end{array}$ \\
\hline 10 & 1 & 0 & & \\
50 & 1.69897 & 10 & 3.72 & \\
100 & 2 & 25 & 4.33 & \\
300 & 2.477121 & 55 & 5.13 & 251.2 \\
500 & 2.69897 & 80 & 5.48 & \\
800 & 2.90309 & 100 & & \\
\hline
\end{tabular}

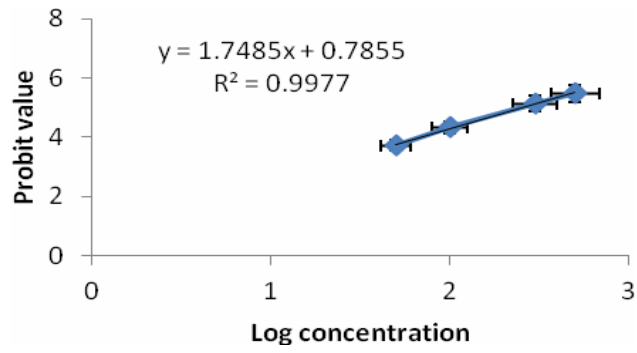

Figure 1. Brine shrimps lethality test.

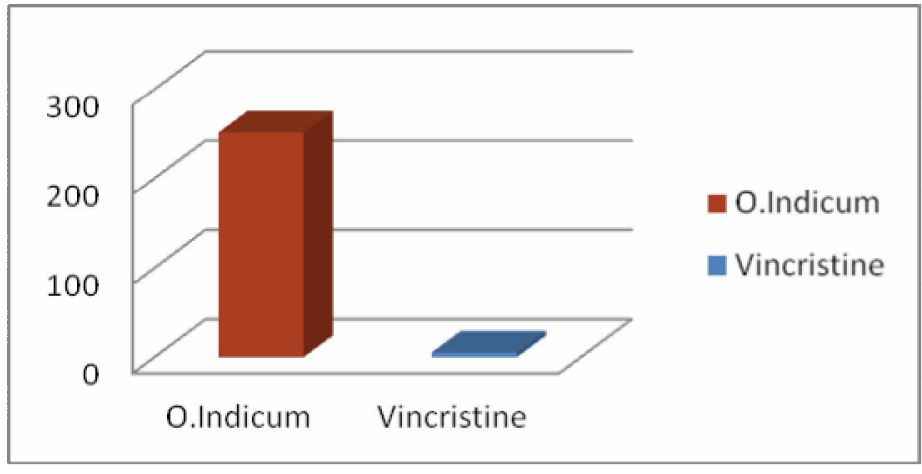

Figure 2. $\mathrm{LC}_{50}$ of $O$. indicum and vincristine sulphate.

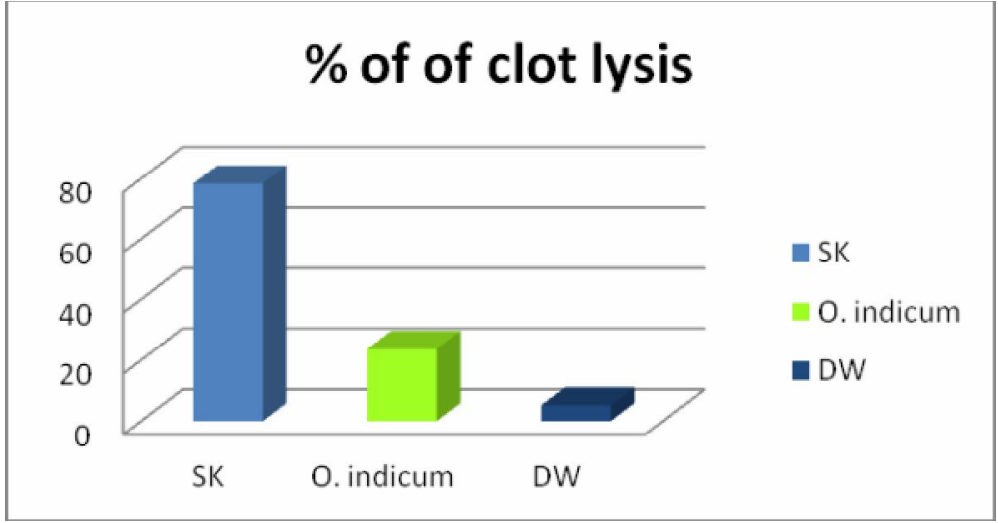

Figure 3. Percentage of clot lysis for $O$. indicum, streptokinase and water. 
Table 2. Percentage of clot lysis of individual volunteer.

\begin{tabular}{lccccc}
\hline No. of volunteer & 01 & 02 & 03 & 04 & 05 \\
\hline$\%$ lysis & $34.12 \pm 0.342$ & $12.46 \pm 0.241$ & $22.59 \pm 0.521$ & $21.29 \pm 0.023$ & $17.25 \pm 0.083$ \\
No. volunteer & 06 & 07 & 08 & 09 & 10 \\
$\%$ lysis & $31.15 \pm 0.117$ & $17.12 \pm 0.836$ & $23.46 \pm .192$ & $27.32 \pm 1.092$ & $30.21 \pm 0.945$ \\
\hline
\end{tabular}

\section{Discussion}

The three main components of a blood clot are platelets, thrombin, and fibrin; each of these components is a key therapeutic target. During thrombus formation, circulating prothrombin is activated to the active clotting factor, thrombin by activated platelets. Fibrinogen is activated to fibrin by the newly activated thrombin. Fibrin is then formed into the fibrin matrix. All this takes place while platelets are being adhered and aggregated (Wanda Rivera-Bou, 2007). Thrombolytic drugs dissolve blood clots by activating plasminogen, which forms a cleaved product called plasmin. Plasmin is a proteolytic enzyme that is capable of breaking crosslinks between fibrin molecules, which provide the structural integrity of blood clots. All of the thrombolytics are large proteins, yet their current sources are diverse: SK and its congener anistreplase from bacterial cultures, u-PA from human kidney cell tissue cultures, and t-PA from recombinant DNA. The development of venous thromboembolism (VTE) in a patient with known cancer is the most common presentation when fibrin deposition on tumor cells during their migration in the blood could protect them from elimination by natural killer (NK) or other cytotoxic cells. Anticoagulant drugs could prevent fibrin coagulation and increase the efficiency of cytotoxic effector cells in tumor cell elimination (Gunji and Gorelik, 1988) Soluble fibrin is a marker for disseminated intravascular coagulation and may also affect leukocyte adherence, recognition, and killing of tumor cells (Biggerstaff et al., 2006). The leave extract of $O$. indicum has significant thrombolytic and cytotoxic compounds. From the above discussion it is clear that there is a close relation between thrombus and cancer treatment. So, $O$. indicum may be a good candidate for discovery of drugs for cardiovascular diseases as well as cancer.

\section{Conclusion}

Most of the drugs and treatment process available in Bangladesh for cardiovascular diseases and cancer is very costly. About 150,000 cancer patients out of the present 1 million die annually owing to limited treatment facilities and about 397 patients died out of 100000 in Bangladesh. According the above discussion and on the basis of the results of the research it can be inferred that $O$. indicum may be a good candidate for the further investigation to discover new drugs for cancer and cardiovascular diseases, which can save thousands of life in the world.

\section{Acknowledgement}

Authors are thankful to Department of Pharmacy, International Islamic University Chittagong, Bangladesh for providing necessary facilities to carry out this study.

\section{References}

Ahad, A., Ganai, A., Sareer, O., Najm, Mz., Kausar, Ma., Mohd, M. and Siddiqui, Wa. 2012. Therapeutic Potential of $O$. Indicum: a review. J. Pharmaceut. Res. Opinion 10, 163-172.

Apu, A.S., Muhit, M.A., Tareq, S.M., Pathan, A.H., Jamaluddin, A.T.M. and Ahmed, M. 2010. Antimicrobial activity and brine shrimp lethality bioassay of the leaves extract of Dillenia indica Linn. J. Young Pharm. 2, 50-53.

Biggerstaff, J.P., Weidow, B., Vidosh, J., Dexheimer, J., Patel, S. and Patel, P. 2006. Soluble fibrin inhibits monocyte adherence and cytotoxicity against tumor cells: implications for cancer metastasis. Thrombosis $J$. 4, 12.

Déciga-Campos, M., Rivero-Cruz, I., Arriaga-Alba, M., Castañeda-Corral, G., Angeles-López, G.E., Navarrete A. and Mata, R. 2007. Acute toxicity and mutagenic activity of Mexican plants used in traditional medicine. J. Ethnopharmacol._110, 334-42.

Finney, D. J. Ed. 1952. Probit Analysis. Cambridge, England, Cambridge University Press.

Ghani, A. 1992. Present State-of-the Art of Traditional Medicine Practice in Bangladesh.

Guanella, R., Ducruet, T. and Johri, M. 2011. Economic burden and cost determinants of deep vein thrombosis during 2 years following diagnosis: a prospective evaluation. J. Thromb. Haemost. 9, 2397-2405. 
Gunji, Y. and Gorelik, E. 1988. Role of fibrin coagulation in protection of murine tumor cells from destruction by cytotoxic cells. Cancer Res. 48, 5216-21.

Heit, J.A., Cohenm, A.T. and Anderson, F.A. 2005. On behalf of the VTE impact assessment group. Estimated annual number of incident and recurrent, non-fatal and fatal venous thromboembolism (VTE) events in the US. 106, 267a.

Laurence, D.R. and Bennett, P.N. 1992. Clinical Pharmacology, Seventh Edition, p. 483

Meyer, B.N., Ferrigni, N.R., Putnam, J.E., Jacobsen, L.B., Nichols, D.E. and McLaughlin, J.L. 1982. Brine shrimp: a convenient bioassay for active plant constituents. Planta Med. 45, 31-34.

Michael, B. Bolger Thrombolytic Pharmacology \& chemistry of Streptokinase, APSAC, PA.
Mukul, S.A. and Uddin, M.B. 2007. Medicinal Plant Diversity and Local Healthcare among the people living in and around a conservation area of Northern Bangladesh. Int. J. For. Usuf. Mngt. 8, 50-63.

Prasad, S., Kashyap, R.S., Deopujari, J.Y., Purohit, H.J., Taori, G.M. and Daginawala, H.F. 2006. Development of an in vitro model to study clot lysis activity of thrombolytic drugs. Thromb J. 4, 1-4.

Rickles, F.R. 2006. Mechanisms of cancer-induced thrombosis in cancer pathophysiology. Haemost. Thromb. 35, 103-10.

Wanda, L. and Rivera-Bou, M.D. FAAEM, FACEP; Chief Editor: David FM Brown, MD. 2012. Medscape reference, Thrombolytic Therapy Drugs, Diseases and Procedure. 